\title{
Proposta de Intervenção para Inovação e Sustentabilidade da Vila Caramuru (Mercado do Peixe) na Cidade de Salvador - BA
}

\author{
Intervention Proposal for Innovation and Sustainability at Vila Caramuru \\ (Mercado do Peixe) in the City of Salvador - BA
}

\author{
Thiago Messias Carvalho Soares ${ }^{1}$ \\ Cidinei Paulo Campos ${ }^{1}$ \\ Marta Aparecida Rodrigues de Oliveira ${ }^{1}$ \\ Driele Lima Rocha ${ }^{1}$ \\ Eduardo Oliveira Teles ${ }^{1}$ \\ Marcelo Santana Silva ${ }^{1}$ \\ ${ }^{1}$ Instituto Federal da Bahia, Salvador, BA, Brasil
}

\begin{abstract}
Resumo
O presente trabalho aborda uma proposta de intervenção no âmbito da inovação e da sustentabilidade para a Vila Caramuru, localizada no Bairro do Rio Vermelho, na cidade de Salvador, Bahia. Para tal, foi necessária a realização de levantamento "in loco" das demandas e necessidades dos proprietários e usuários do espaço, por meio de visitas técnicas, registro fotográfico e aplicação de questionário. Como resultado, obteve-se um diagnóstico da Vila Caramuru, apontando-se as reais necessidades e as demandas para melhor funcionamento do local. Em seguida, foi apresentada a proposta de intervenção, tendo como foco a inovação e a sustentabilidade, promovendo, também, a integração do espaço da associação dos pescadores, ora abandonado e isolado pela última intervenção realizada pela Prefeitura. Nas considerações finais, a presente proposta destaca a humanização da Vila com a participação harmônica dos atores envolvidos no ambiente com mais áreas verdes, acessibilidade e áreas de convivência.
\end{abstract}

Palavras-chave: Inovação. Proposta de Intervenção. Sustentabilidade. Vila Caramuru.

\begin{abstract}
The present work addresses an intervention proposal in the scope of innovation and sustainability for Vila Caramuru, located in the Bairro do Rio Vermelho, in the city of Salvador, Bahia. For this, it was necessary to carry out a survey "in loco" of the demands and needs of the owners and users of the space, through technical visits, photographic registration and questionnaire application. As a result, a diagnosis of Vila Caramuru was obtained, pointing out the real needs and demands for better functioning of the place. Then, the intervention proposal was presented, focusing on innovation and sustainability, also promoting the integration of the space of the fishermen's association, now abandoned and isolated by the last intervention carried out by the City Hall. In the final considerations, the present proposal highlights the humanization of the Village with the harmonious participation of the actors involved in the environment with more green areas, accessibility and living areas.
\end{abstract}

Keywords: Innovation. Intervention Proposal. Sustainability. Vila Caramuru.

Área Tecnológica: Empreendedorismo e Ambiente de Inovação. 


\section{Introdução}

Fatores como crescimento desordenado e desigualdade social levam à desarticulação do espaço urbano e à desvalorização de áreas históricas. Por isso, nas últimas décadas, as intervenções para requalificação dos espaços públicos urbanos vêm sendo uma constante nas grandes cidades (BORTOLOZO, 2016).

A cidade de Salvador tem passado por várias transformações de seus espaços públicos ao longo dos anos. O crescimento da cidade provocou grandes mudanças nas vias públicas e espaços de lazer com o propósito de requalificar a cidade para atrair turistas, já que o ramo do turismo é a sua vocação econômica. É possível observar intervenções em toda a orla marítima da cidade, no sentido de ressignificar os espaços. As intervenções vêm sendo realizadas, em alguns casos, por meio de parcerias público/privadas.

O trabalho em tela é fruto de um projeto de pesquisa do grupo de estudo do Mestrado Profissional em Propriedade Intelectual e Transferência de Tecnologia para Inovação (PROFNIT), ponto focal no Instituto Federal da Bahia (IFBA), para mapear e propor projetos de intervenção em diferentes espaços públicos na cidade de Salvador - BA. O local desta pesquisa é o antigo Mercado do Peixe, atual Vila Caramuru, localizada no Bairro do Rio Vermelho.

O Bairro do Rio Vermelho é um dos mais movimentados das noites de Salvador. O local já passou por alguns processos de modificação, porém, em visita in loco, foram identificados fatores que podem tornar o ambiente ainda mais atraente aos frequentadores, que, segundo a pesquisa aplicada, correspondem a cerca de $70 \%$ de turistas. As ações de intervenção envolvem conceitos de inovação e de sustentabilidade apresentados no referencial teórico. A intervenção se faz necessária para atender às demandas de comerciantes, clientes e visitantes. O Projeto de Intervenção certamente proporcionará maior visibilidade da Vila Caramuru, que leva consigo uma história que faz parte da vida dos proprietários que têm o seu ponto de venda no local, desde o tempo em que era uma feirinha, e dos pescadores que, segundo Santos (2014), são os principais fundadores do bairro.

Este trabalho tem como objetivo desenvolver uma proposta de intervenção para a Vila Caramuru, a partir do levantamento/observação do espaço e da percepção dos proprietários dos estabelecimentos, com o intuito de sugerir estratégias inovadoras e sustentáveis para atender às reais necessidades e às demandas do local.

\section{Referencial Teórico}

De acordo com a Comissão Mundial sobre Meio Ambiente e Desenvolvimento (CMMD, 1991), o desenvolvimento sustentável é aquele que atende aos anseios da geração presente sem esgotar a possibilidade de as gerações futuras também terem seus anseios atendidos. Portanto, o conceito de desenvolvimento aqui levado em consideração é o de que as intervenções no espaço devem zelar pela preservação dos recursos naturais e pela disponibilidade do uso desses espaços de forma isonômica.

Para Tosta e Noleto (2017), o debate da sustentabilidade deve priorizar a diminuição de impacto na crescente urbanização sobre os recursos naturais, buscando, para isso, o uso de 
novas tecnologias que possibilitem que os recursos sejam utilizados de forma mais consciente visando à preservação.

Buscar a sustentabilidade urbana significa a preservação e restauração do ambiente natural ao mesmo tempo que se constrói ou regenera o ambiente urbano, fortalecendo as relações sociais, o sentimento de pertencimento e responsabilidade da população com a cidade e o macrocontexto na qual esta se insere. (TOSTA; NOLETO, 2017, p. 131)

O conceito de inovação levado em consideração neste trabalho é o de inovação como a habilidade de criar e de acrescentar conhecimentos para resolver com criatividade os problemas, conforme alega Mendez (2002 apud DALLABRIDA; COVAS; COVAS, 2017), que também considera a inovação uma ferramenta indispensável para revigorar economicamente as cidades, bem como para obter cidades mais sustentáveis e inclusivas. Para Dallabrida, Covas e Covas (2017), os meios de inovação do território devem ter um caráter coletivo resultante de fatores sociais, históricos, culturais, econômicos e ambientais.

O espaço público é o lugar onde se vive a vida em sociedade. Ao longo da história e dos diferentes contextos históricos e culturais, é o local em que os cidadãos de uma localidade interagem entre si. Todo espaço público passa por constantes mudanças ao longo da história em função de transformações sociais, econômicas e ambientais (FERNANDES, 2012).

Conforme afirma Silva (2014), o espaço público deve ser compreendido como uma área de sociabilidade com potencial de exercer várias funções. O processo de apropriação desse espaço ocorre por meio das formas de uso que os habitantes da cidade fazem nas suas relações diretas com o lugar. São essas relações que dão sentido ao espaço público, porém, a apropriação do espaço público só é possível se ele for constituído de acessibilidade. Nesse caso, o sentido de acessibilidade extrapola a dimensão do simples acesso físico, significando espaços abertos de uso coletivo, ou seja, espaço que toda a população possa usufruir.

A própria sociedade é responsável por impor barreiras, imposta de forma simbólica por meio da segregação e desta forma privatizando o espaço. Esse espaço passa a ser socialmente fragmentado, desta forma acessibilidade passa a ser parcial. O Estado constitui papel importante na apropriação do espaço, exercendo o papel de agente produtor do espaço em conjuntos com a população, além de administrador desse espaço por excelência. (SILVA, 2014, p. 9)

De acordo com Fernandes (2012), a requalificação do espaço público busca reinserir as qualidades urbanas a um determinado local, trazendo mudanças na paisagem, na cultura, na sociedade e na economia desse local. A requalificação cria condições para o desenvolvimento de atividades econômicas, gerando emprego e inclusão dos habitantes ao setor produtivo e, também, melhor qualidade de vida aos seus habitantes.

Requalificar espaços públicos de ambientes nos quais o turismo predomina gera maior visibilidade à região e influencia, direta e instantaneamente, em sua economia. Segundo Silva (2014), é possível desenvolver clusters atrativos com diferenciais turísticos para estimular a economia de uma região. A autora pontua que o turismo proporciona desenvolvimento a outras atividades econômicas, como comércios, agências, meios de hospedagem, infraestrutura, além de promover o desenvolvimento socioeconômico local por meio dos setores que se articulam 
entre si. Ela afirma ainda que os aglomerados formados podem facilitar o surgimento de incubadoras e de ideias inovadoras e empreendedoras (SILVA, 2014).

Estes aspectos, impulsionados pela tecnologia da informação e da inovação, irão determinar a participação no mercado de turismo, de forma integrada com outras competências, criando vantagem competitiva para o destino. A competitividade de um destino turístico deve estar alinhada à sustentabilidade e ao desenvolvimento harmonioso, ou seja, o desenvolvimento da localidade não deve ser apenas sustentável economicamente, mas também em termos de políticas sociais, tecnologia, natureza, ecologia e cultura. (SILVA, 2014, p. 353)

Conforme alegam Santo e Ribeiro (2015, p.16), não basta reformar ou requalificar um espaço público, é necessário ir além, é preciso compreender a dinâmica do lugar e das pessoas "[...] a fim de que os espaços públicos a serem projetados e/ou revitalizados reflitam as necessidades e os anseios dos seus usuários, para só assim serem realmente utilizados".

\section{Objetivo}

Este trabalho tem como objetivo desenvolver uma proposta de intervenção na Vila Caramuru, a partir do levantamento/observação do espaço e da percepção dos proprietários dos estabelecimentos, com o intuito de sugerir estratégias inovadoras e sustentáveis para atender às reais necessidades e demandas do local.

\section{Metodologia}

Para a realização do trabalho, procurou-se analisar as características e os conceitos relativos ao espaço público para servir de base na proposta de intervenção do espaço público em questão. Em seguida, procedeu-se pesquisa sobre a história do lugar e as intervenções realizadas ao longo dos anos.

Realizou-se visita técnica no local com a finalidade de conhecer o estado do espaço público, como quantidade de equipamentos, localização, função e registro fotográfico. Em outra etapa, realizou-se uma segunda visita com o propósito de entrevistar os comerciantes da Vila, identificando, assim, suas percepções e necessidades.

As informações obtidas nas visitas técnicas foram tratadas nesta pesquisa de forma global sem a identificação dos proprietários e dos estabelecimentos participantes. Para os dados quantitativos, foi utilizada a estatística descritiva e, para os dados qualitativos, foi usada a Análise de Conteúdo, que, de acordo com Bardin (2010), é uma metodologia de pesquisa usada para descrever e interpretar o conteúdo de todos os tipos de documentos e textos. Foi utilizada como ferramenta de análise dos dados a Matriz SWOT, em português FOFA, que se baseia na análise do ambiente interno dos empreendimentos, identificando suas forças $e$ suas fraquezas, $e$ da análise do ambiente externos, identificando suas oportunidades e suas ameaças (SEBRAE, 2019). A partir dessa análise, foram sugeridas estratégias e/ou ações para a intervenção.

As pesquisas de campo contabilizaram duas visitas à Vila Caramuru, localizada no Bairro do Rio Vermelho, em Salvador. A primeira visita foi em 24 de novembro de 2018 para obser- 
vação do local e levantamento fotográfico e a segunda visita foi em $1^{\circ}$ de dezembro de 2018 para entrevistar os comerciantes locais.

Foi aplicado um questionário no qual cada comerciante expôs suas opiniões sobre infraestrutura, tecnologia, segurança, atendimento, acessibilidade, divulgação do espaço e relacionamento com o entorno. Tal questionário foi fundamental para embasamento da pesquisa, por revelar dados e informações do cotidiano do espaço. O local possui 14 estabelecimentos e o questionário foi aplicado em 13 deles, portanto, apenas um proprietário não foi entrevistado, visto que não se encontrava no local no dia da visita.

Partindo das informações colhidas em campo e confrontando-as com elementos colhidos nas etapas anteriores, foi elaborado o projeto de intervenção, visando à inovação e à sustentabilidade para o empreendimento.

\section{Diagnóstico}

Nesta etapa, serão apresentados um breve histórico do local e os principais aspectos observados nas visitas.

\subsection{Histórico do Local}

O Mercado do Peixe teve início nos anos de 1950, originalmente com o nome de Mercado Municipal do Rio Vermelho, localizado no Largo da Mariquita, onde se vendia peixe, carne, frutas e verduras. Em 1980, o mercado foi transferido para o outro lado da rua, de frente para o mar.

Figura 1 - Primeiro Mercado situado no Largo da Mariquita

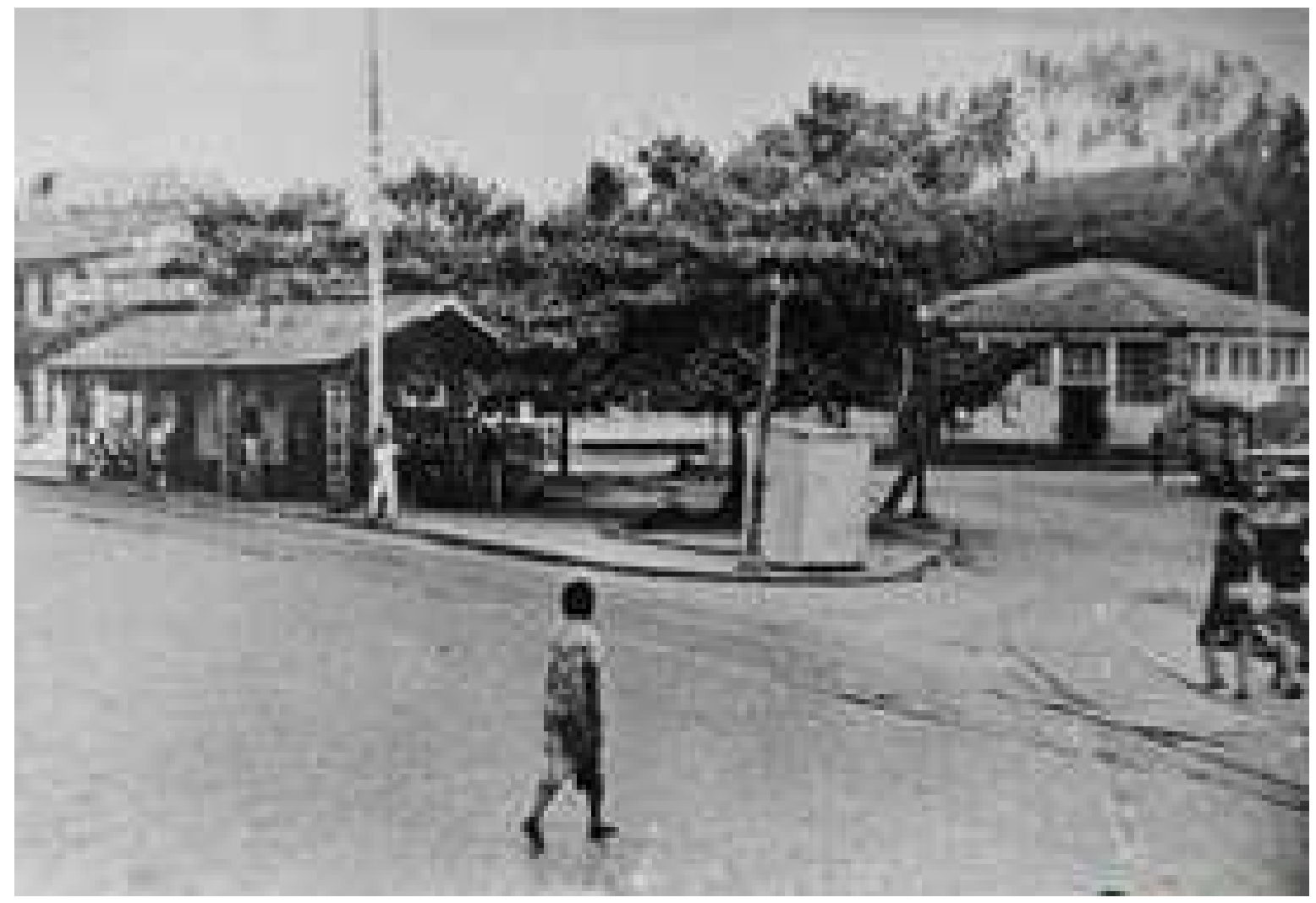

Fonte: Blog do Rio Vermelho (2015) 
Figura 2 - Mercado do Peixe em frente à Praia

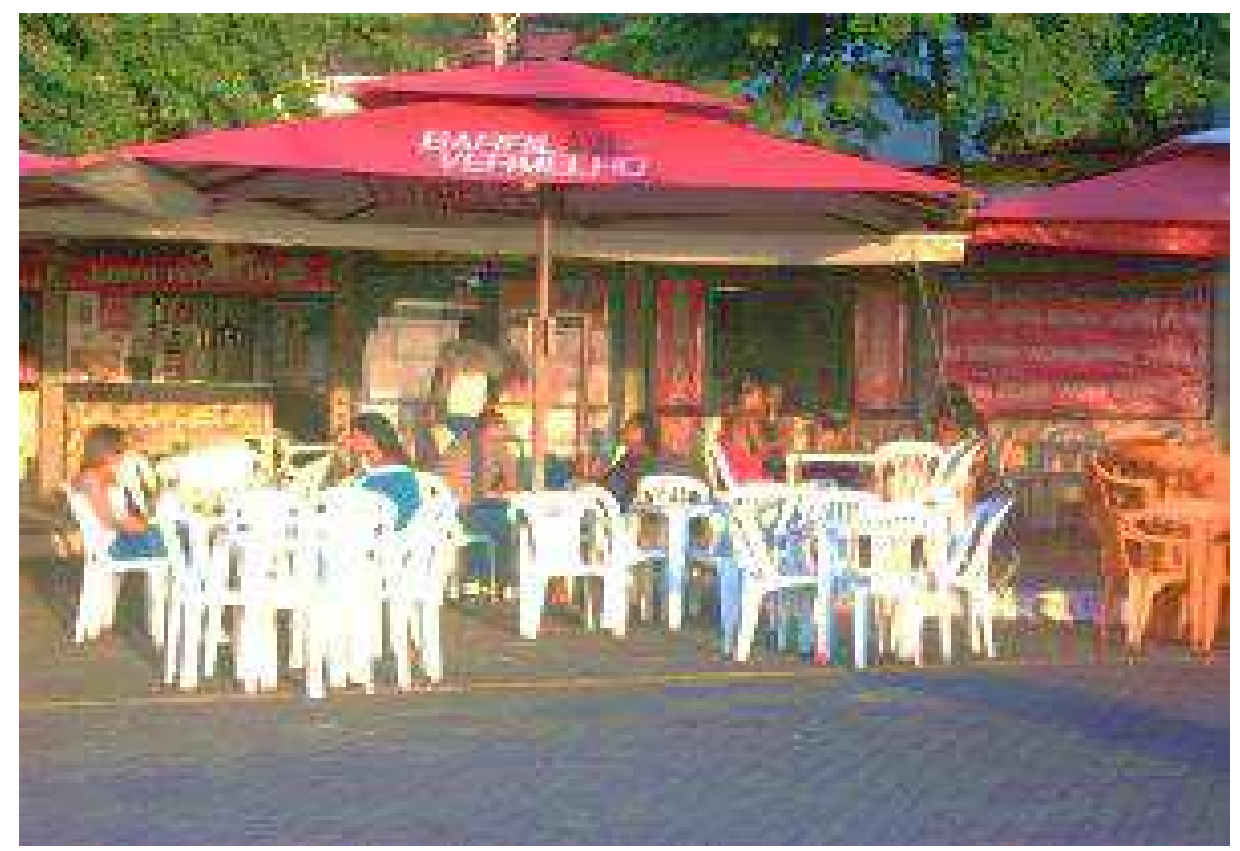

Fonte: Barros (2009)

Em 2010, a prefeitura firmou uma parceria com uma marca de cerveja para substituir os antigos barracões por boxes de alvenaria, dando como contrapartida a exclusividade da venda da bebida dessa marca de cerveja até 2020. Essa reforma ampliou a quantidade de boxes de 13 para 36, e a taxa mensal cobrada aos proprietários, na época, teve previsão de aumento de $\mathrm{R} \$ 400,00$ para cerca de $\mathrm{R} \$ 3.000,00$ (BARROS, 2009).

Com essa reforma, o lugar ficou esteticamente mais bonito, mas a infraestrutura continuou precária. Os locais para preparação dos alimentos nos boxes eram pequenos e a condição de higiene deixava muito a desejar (BLOG DO RIO VERMELHO, 2016).

Figura 3 - Mercado do Peixe após reforma em 2010

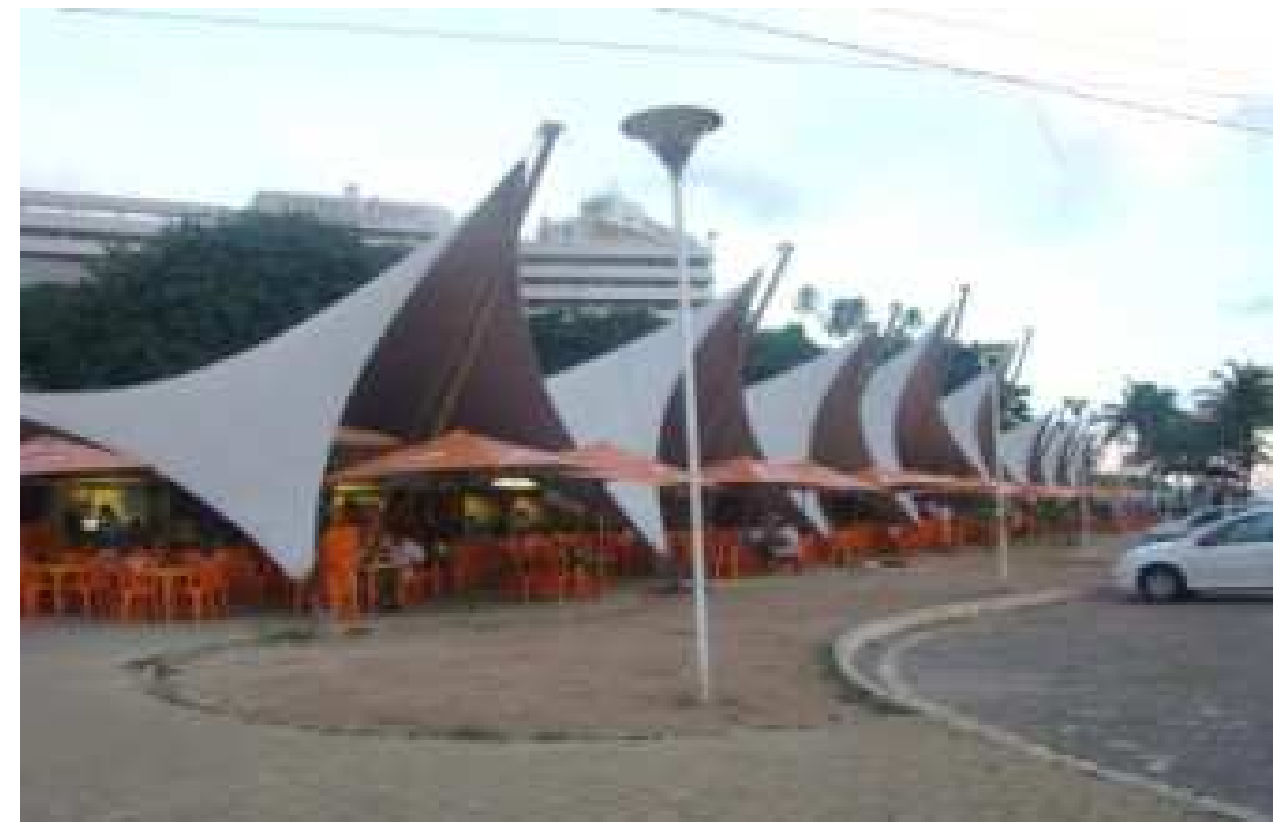

Fonte: Blog do Rio Vermelho (2016) 
Em julho de 2015, a prefeitura iniciou uma nova intervenção no local e, após essa intervenção, apenas quatro comerciantes que atuavam no mercado permaneceram no local. A concessão de um box na nova Vila Caramuru passou a custar cerca de R $\$ 250$ mil, além do condomínio pago à concessionária que administra o local. O antigo Mercado do Peixe está sob concessão de duas empresas privadas que durante 15 anos irão locar os estabelecimentos e administrar o lugar financeira e estruturalmente (GUSMÃO, 2017).

De acordo com Gusmão (2017), por meio de um olhar superficial, o bairro do Rio Vermelho em Salvador, após a intervenção realizada pela prefeitura a partir de 2015, apresenta melhorias nas vias e praças, porém, permanecem problemas estruturais que a administração pública negligenciou em função das expectativas do grande capital.

A lógica parece bastante simples: desqualificar o "velho" Rio Vermelho, salientando as empreitadas da prefeitura com vistas a higienizar socialmente o bairro e impor formas autoritárias de apropriação do solo urbano. Muito embora esse raciocínio seja escancarado na postura repressiva da prefeitura, que expulsou comerciantes populares e impôs um ethos fortemente equalizado aos padrões estéticos elitistas, o tema ainda divide opiniões. (GUSMÃO, 2017, p. 534)

Figura 4 - Mercado do Peixe após reforma em 2015

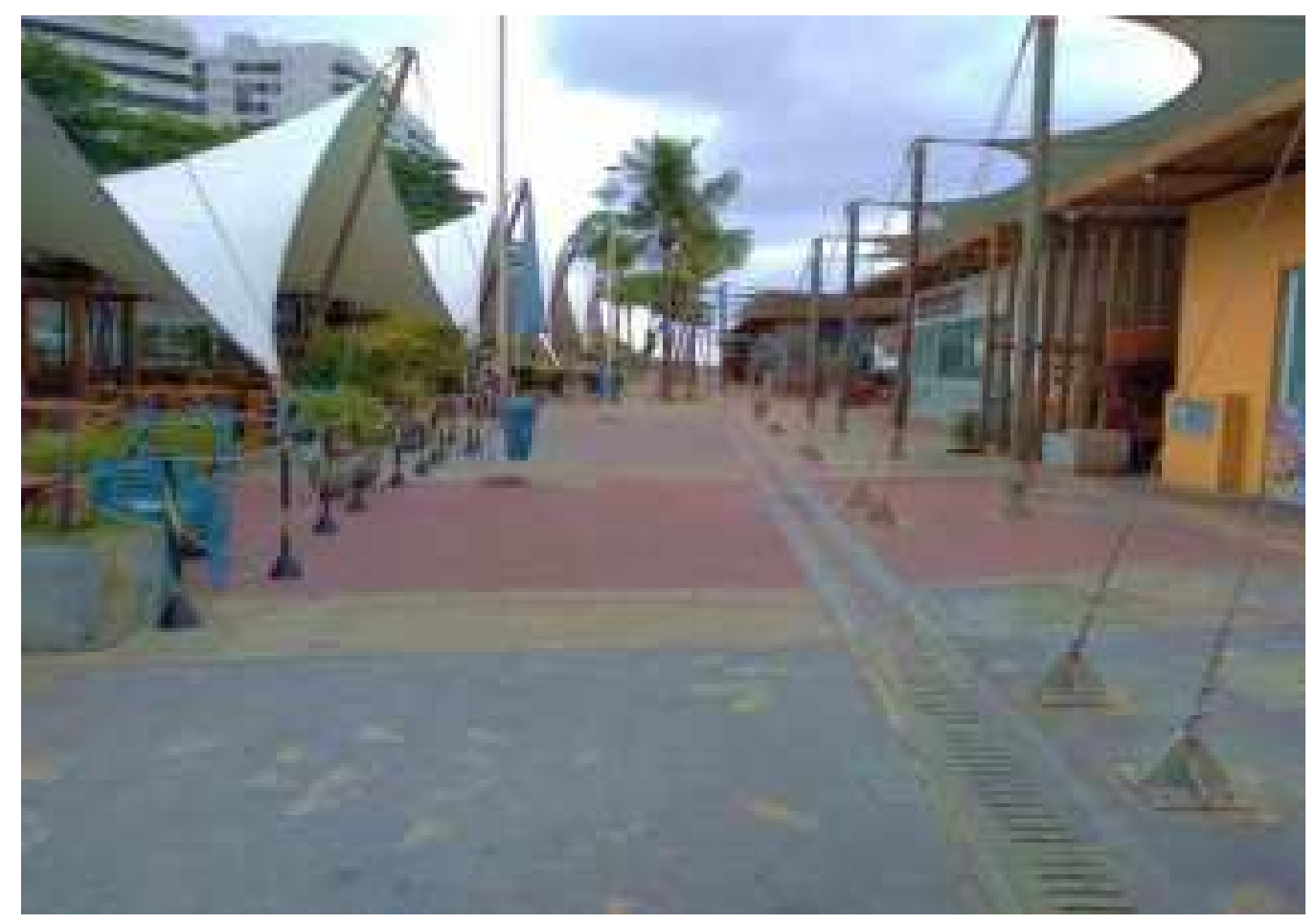

Fonte: Arquivo pessoal dos autores deste artigo 
Figura 5 - Atual Vila Caramuru

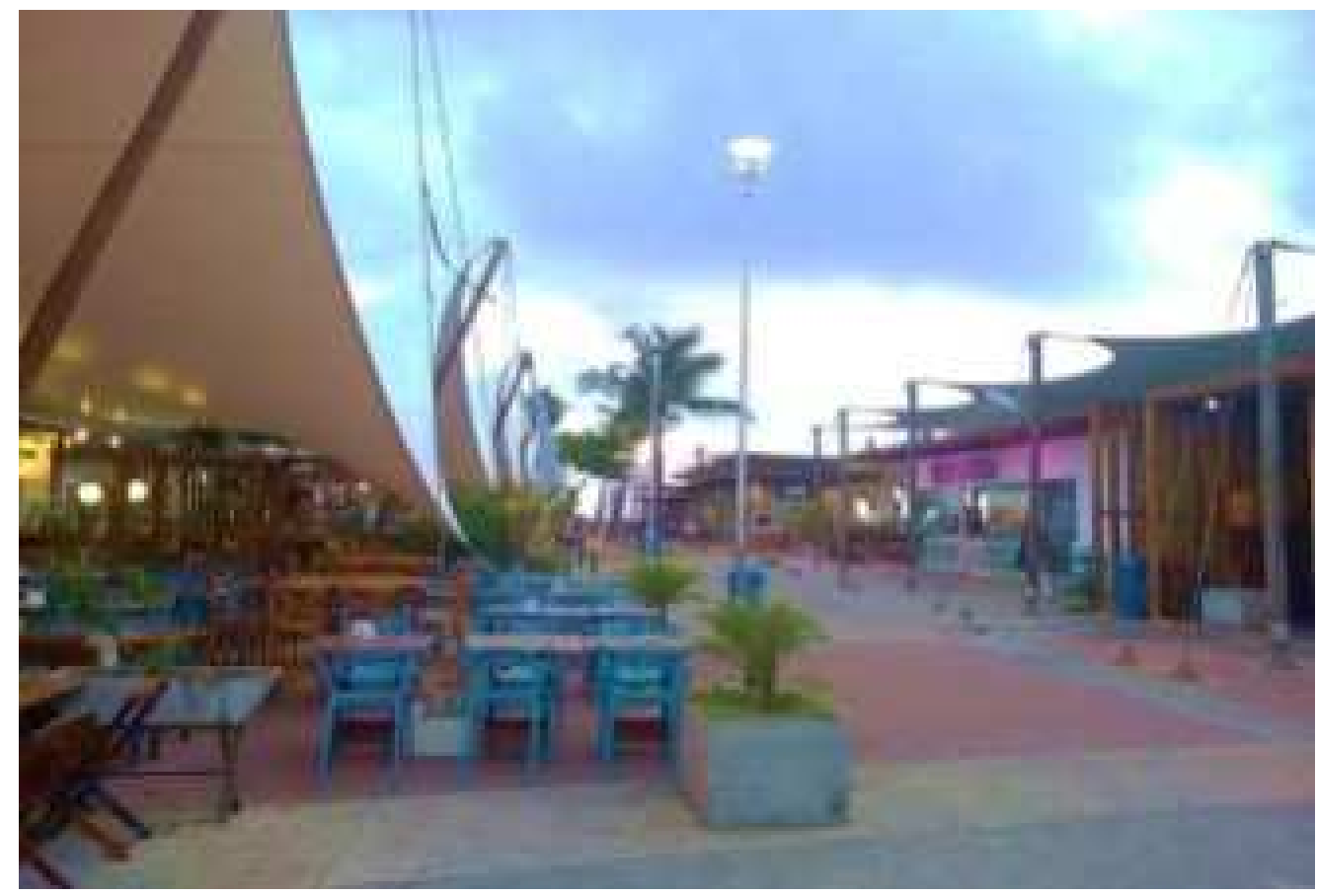

Fonte: Arquivo pessoal dos autores deste artigo

A Concessionária que venceu a licitação para a requalificação do local investiu na reforma dos restaurantes/bares existentes e na construção de quiosques padronizados. $\mathrm{O}$ valor investido na Vila Caramuru foi de R\$1,520 milhão (PACHECO, 2016). Atualmente, o local possui 14 estabelecimentos, sendo 11 bares/restaurantes e três quiosques (Figura 6).

Figura 6 - Planta geral esquemática da Vila Caramuru (após última intervenção)

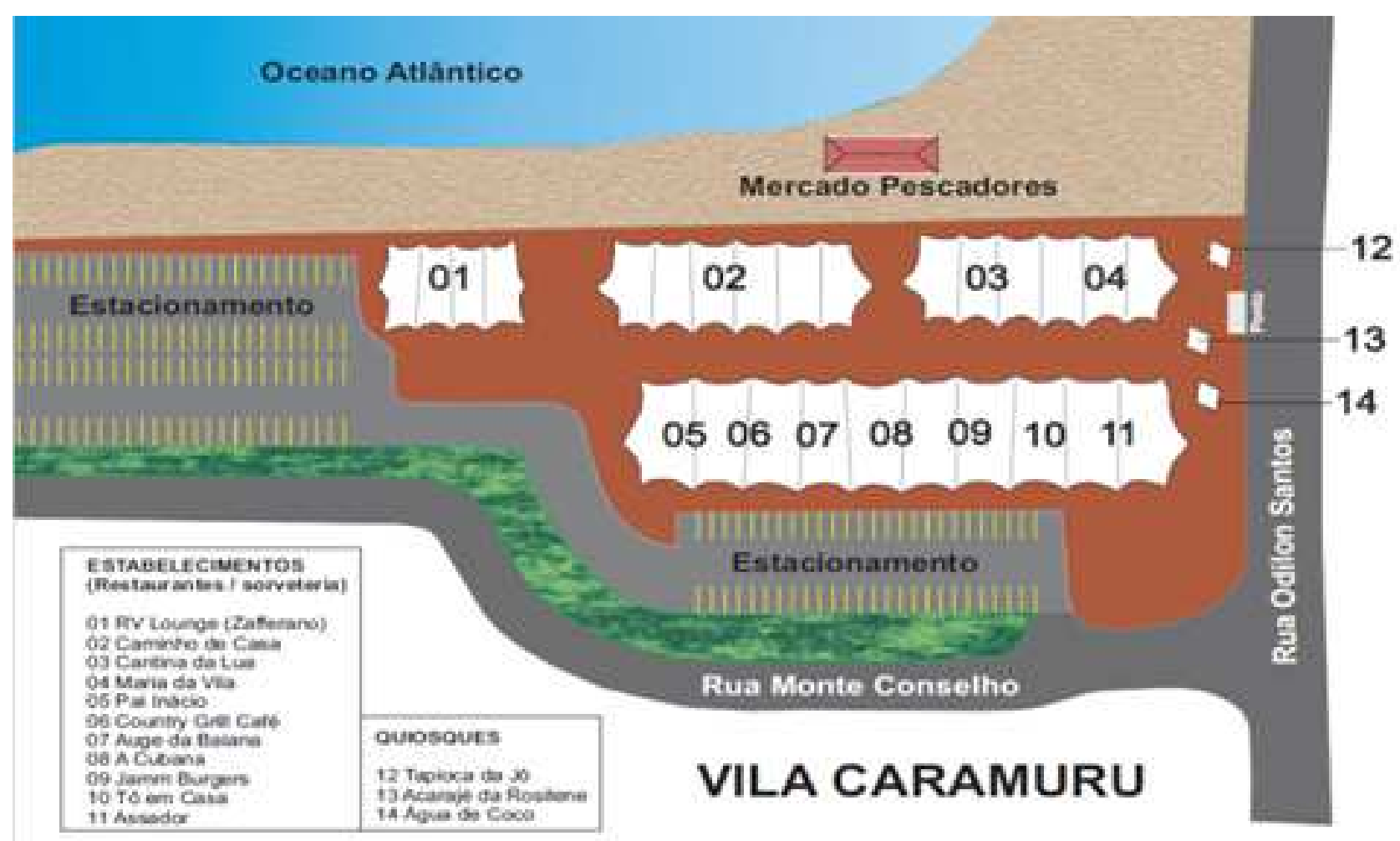

Fonte: Elaborada pelos autores deste artigo 


\subsection{Principais Aspectos Observados}

Os resultados das entrevistas realizadas com os comerciantes ou com os gerentes dos estabelecimentos da Vila Caramuru possibilitaram realizar o levantamento da situação do local e dos estabelecimentos, permitindo a elaboração da proposta de intervenção.

\subsubsection{Infraestrutura}

A infraestrutura local ainda necessita de algumas melhorias para oferecer maior conforto e segurança aos comerciantes e aos clientes que frequentam os estabelecimentos. Dos tópicos observados, destaca-se a cobertura, a acessibilidade e os sanitários.

A cobertura apresenta uma bela estética com suas curvas e design moderno e passa aos usuários aspecto de ambiente refinado. Todavia, nesse tópico, a funcionalidade do elemento cobertura é seriamente comprometida em períodos chuvosos, pois devido à sua geometria, o ambiente interno acaba molhando em período de chuvas. Os estabelecimentos mais afetados são os próximos à maré, os quais recebem de frente o maior impacto da intempérie.

A acessibilidade é parcialmente atendida. Ainda faltam medidas para as Pessoas com Deficiência $(\mathrm{PcD})$ e idosos. Os principais aspectos observados foram a falta de rampas em locais estratégicos e sanitários específicos para o público supracitado.

Por fim, os sanitários são insuficientes para a demanda. No primeiro contato, o indivíduo tem dificuldade até de localização dos banheiros. Os poucos sanitários existentes localizam-se próximo de certos estabelecimentos destacando que alguns deles ficam fechados e com as chaves na posse dos estabelecimentos.

Dado o exposto, observa-se que, apesar do funcionamento normal da Vila Caramuru, ainda faltam medidas corretivas em termos de infraestrutura para beneficiar e melhorar o uso dos recursos do local pelos comerciantes, funcionários, clientes e visitantes.

Figura 7 - Coberturas dos bares e restaurantes da Vila Caramuru
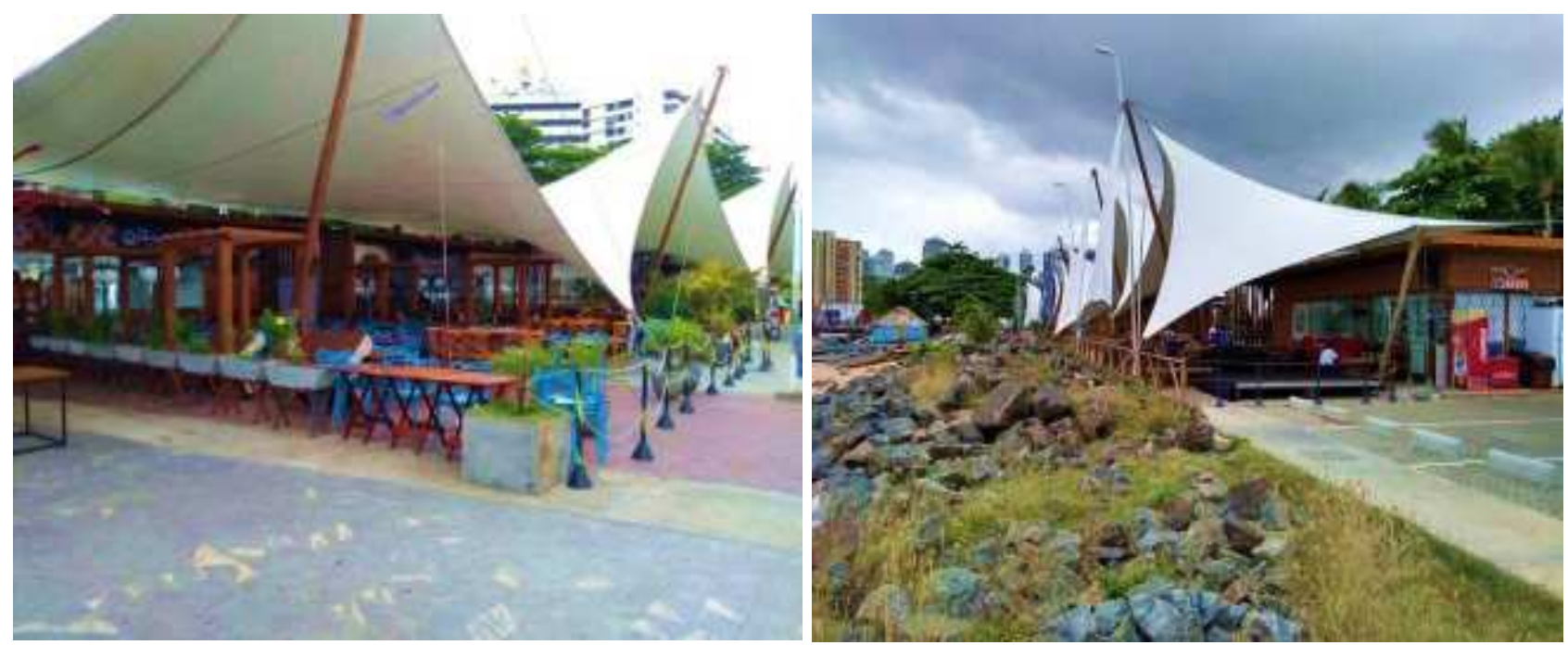

Fonte: Arquivo pessoal dos autores deste artigo 


\subsubsection{Diferencial Apontado pelos Estabelecimentos}

Na Vila Caramuru foram coletadas informações sobre o diferencial apontado pelos comerciantes sobre o seu produto ou forma de atendimento. Observou-se que $50 \%$ dos estabelecimentos afirmam ter comida típica e regional, usando temperos e ingredientes que os diferenciam dos demais. Percebe-se que $7 \%$ afirmam que seu diferencial está na grande variedade de sabores do seu produto.

Identificou-se que, em $7 \%$ dos estabelecimentos, o diferencial é o uso de espaço interno para apresentação de artistas e bandas. Esse tópico causa algumas polêmicas, pois o volume do som pode incomodar o entorno, apesar de existir estabelecimentos que se aproveitam do som dos vizinhos para atrair clientes.

Ademais, relata-se como diferencial a existência de pedidos on-line (por meio de tablet) em apenas um estabelecimento da Vila Caramuru, bem como oferta dos produtos por $15 \%$ dos estabelecimentos em sites de e-commerce e oferta de degustações para os clientes sem compromisso ou pagamento. Não foi percebido diferencial na oferta do produto ou serviço em $21 \%$ dos estabelecimentos.

\subsubsection{Divulgação do Espaço}

A divulgação dos estabelecimentos da Vila ocorre em $78 \%$ dos estabelecimentos basicamente com o uso de redes sociais (Facebook e Instagram), sites na internet, no rádio e em eventos.

\subsubsection{Prática de Sustentabilidade}

As ações de sustentabilidade estão timidamente presentes na Vila. Destaca-se principalmente a coleta de óleo das frituras em $86 \%$ dos estabelecimentos. Uma vez por semana, uma empresa passa no local para coletar os óleos usados e em troca fornece sabão aos comerciantes. Existe separação das garrafas de vidros, porém não há a prática da coleta seletiva. Ademais, em um dos estabelecimentos, é utilizado carvão de reflorestamento para assar carne, e as tentativas de retirada do canudo plástico em $14 \%$ dos estabelecimentos já refletem o despertar de uma consciência sustentável ainda muito incipiente na Vila Caramuru.

\subsubsection{Interferência do Entorno}

Observou-se a negativa interferência de forte odor proveniente do canal do Lucaia, que é lançado ao lado da Vila. Tal comentário foi unânime entre todos os entrevistados. Como visitantes e clientes, os membros da equipe de pesquisa já tinham ido à Vila e sentido os maus odores. Além disso, grande parte dos estabelecimentos afirma que o excesso de vendedores ambulantes atrapalha $e$ incomoda as vendas $e$ os clientes. 
Figura 8 - Canal do Lucaia ao lado da Vila Caramuru

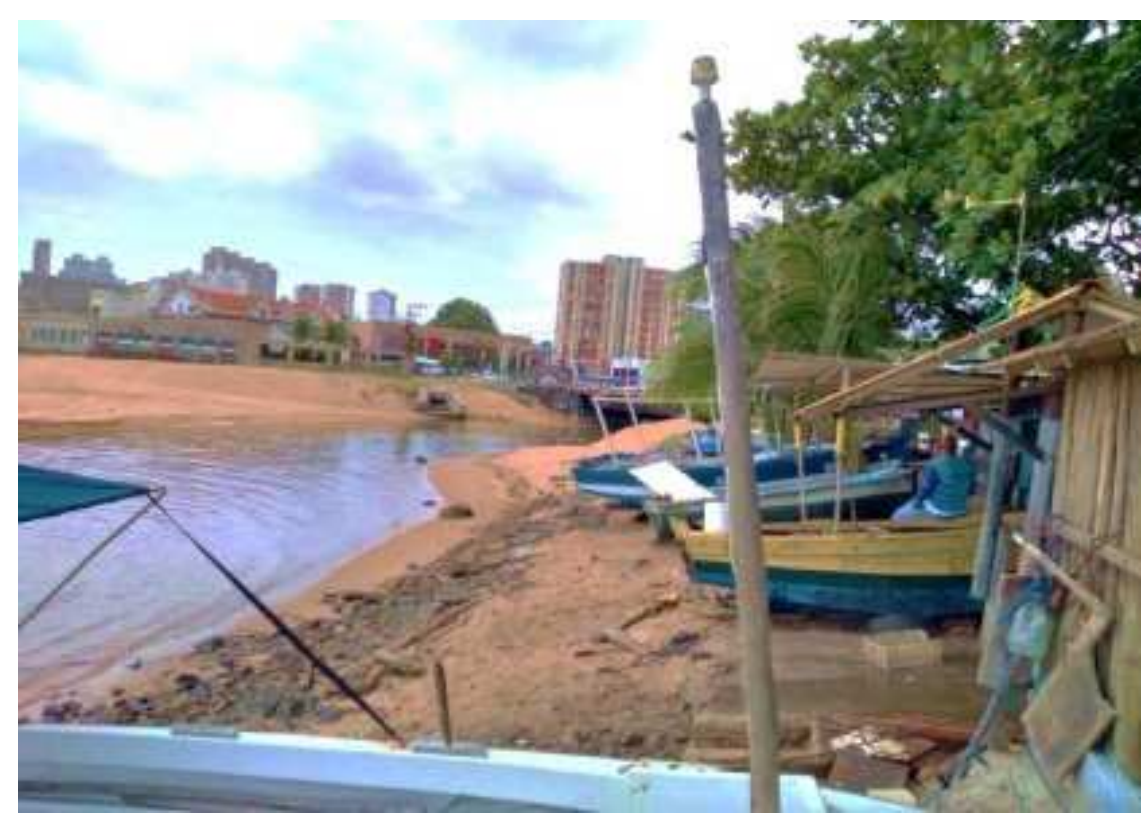

Fonte: Arquivo pessoal dos autores deste artigo

Figura 9 - Colônia dos Pescadores



Fonte: Arquivo pessoal dos autores deste artigo

\subsubsection{Colônia dos Pescadores}

A Colônia dos Pescadores adjacente à Vila Caramuru não foi complementada na última reforma. Os pescadores alegam abandono da prefeitura e reclamam da falta de infraestrutura necessária para facilitar o trabalho deles. Ressalta-se que a reforma do Colônia não entrou no contexto do empreendimento, já que, segundo eles, praticamente não há vendas de peixes para os estabelecimentos vizinhos, portanto, eles estão isolados e totalmente independentes. 


\subsubsection{Interação entre os Estabelecimentos}

Os estabelecimentos interagem positivamente entre si na troca de insumos necessários para a confecção de seus produtos ou até mesmo seu atendimento. Ainda não existe uma associação formalmente constituída dos comerciantes locais, entretanto, há encontros e reuniões entre os dirigentes para tomada de decisões em comum. Dos aspectos negativos dessa interação, observou-se, nas respostas, as reclamações dos donos dos quiosques sobre o uso dos sanitários, segundo eles, os restaurantes controlam esse uso, porque ficam com as chaves. Identificou-se também as reclamações de alguns dirigentes que oferecem atrações musicais, eles alegam que os estabelecimentos vizinhos se beneficiam dos seus shows e não cobram ingressos, já que a divisão entre um restaurante e outro é de apenas meia parede.

\section{Proposta de Intervenção para Inovação e Sustentabilidade}

A partir da observação do local e das entrevistas realizadas, constatou-se que, apesar dos investimentos realizados recentemente para requalificação do local, ainda há necessidade de melhoria, o que deu embasamento para a proposta de intervenção estruturada em três eixos: infraestrutura, tecnologia e integração com agentes externos.

\subsection{Infraestrutura}

No tocante ao problema da cobertura inadequada para dias de chuvas, foi proposto o uso de cobertura com telha cerâmica, calhas para captação de águas pluviais e placas solares para geração de energia visando à sustentabilidade do local (Figura 10).

Em relação à acessibilidade local, propõe-se a instalação de piso tátil, implantação de mapa tátil e criação de mais rampas de acesso para Pessoas com Deficiência $(\mathrm{PcD})$ e idosos. Além disso, propõe-se a construção de banheiros com acessibilidade e adequação dos existentes para $\mathrm{PcD}$.

Os pescadores precisam fazer parte da Vila Caramuru, para isso, sugere-se a reforma com integração da colônia de pescadores, incluindo a construção de uma praça voltada ao lazer em torno da colônia, bem como a execução de píer e do quebra-mar para as embarcações, com o intuito de integrá-los ao espaço e promover a venda dos seus produtos (Figura 10). 
Figura 10 - Planta geral esquemática da proposta de intervenção na Vila Caramuru

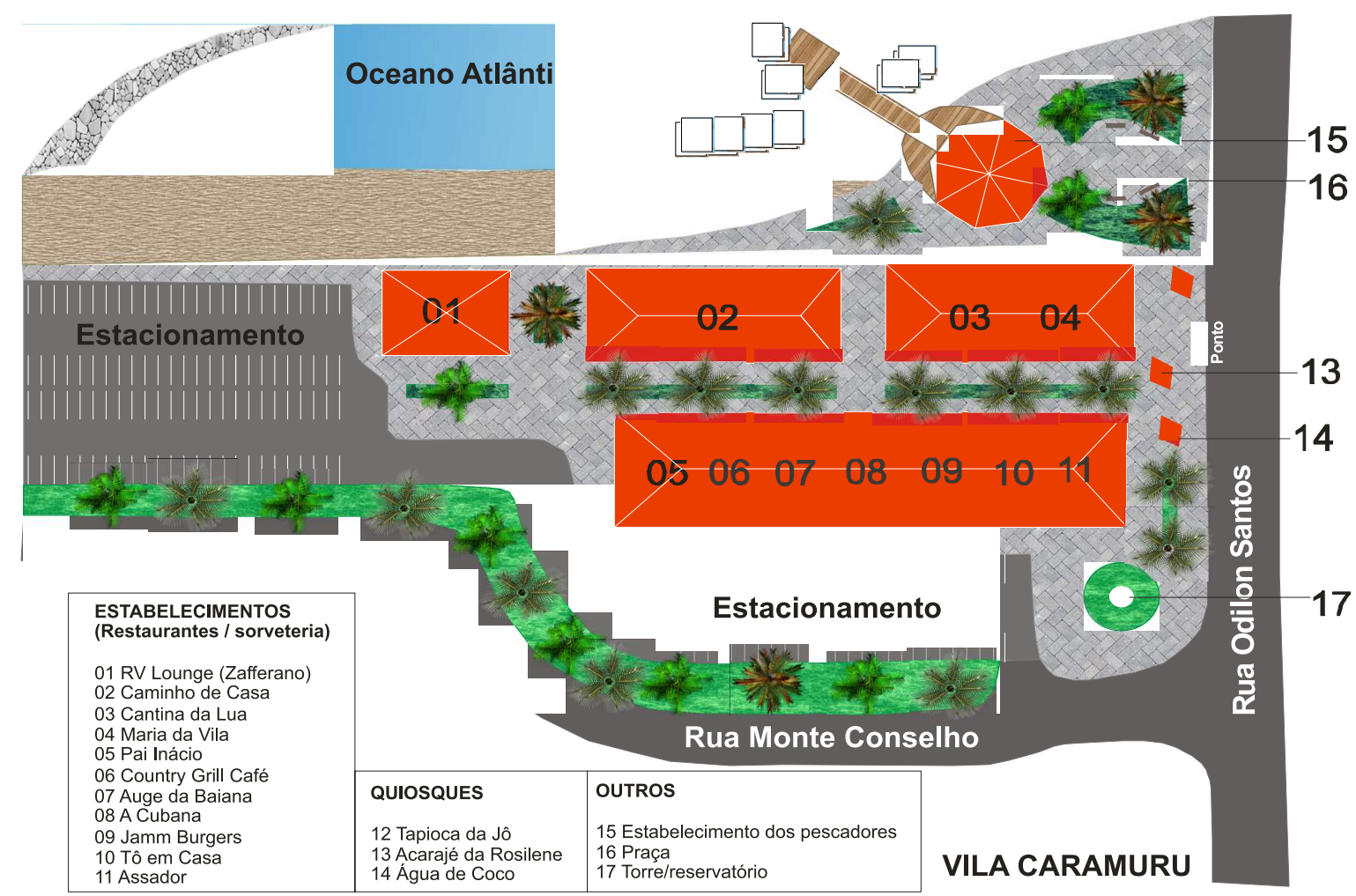

Fonte: Elaborada pelos autores deste artigo

O sistema de esgoto sanitário de Salvador é formado por uma rede coletora, composta de 28 bacias sanitárias integradas aos emissários do Rio Vermelho e da Boca do Rio. O emissário do Rio Vermelho opera desde 1975, com 7,5 mil litros de efluentes por segundo. "Após condicionamento, os esgotos são conduzidos ao emissário e lançados ao mar em uma profundidade de 27 metros, a 2.350 metros da costa, obedecendo às exigências da legislação ambiental" (EMBASA, 2013, p. 49). Apesar de ser realizado condicionamento antes do lançamento do esgoto no emissário do Rio Vermelho, percebe-se, por meio do mau odor oriundo do canal adjacente à Vila Caramuru, que esse procedimento não é eficiente, para isso, aponta-se como solução realizar uma avaliação do sistema para que sejam feitos ajustes no sentido de fazer o tratamento do esgoto de forma mais eficiente.

\subsection{Tecnologias}

Apresenta-se como proposta o uso de algumas tecnologias como a instalação de um sistema de captação e tratamento de águas pluviais para reuso com previsão de utilização desta para irrigação das áreas verdes e descargas dos vasos, por meio da construção de reservatórios superior e inferior com sistema de filtragem e câmaras de separação de água potável e de reuso.

Outra tecnologia muito difundida e que se propõe neste trabalho, para aplicação na Vila Caramuru, é o sistema de geração de energia solar, por meio da instalação de placas fotovoltaicas embutidas nas próprias telhas cerâmicas.

Ademais outras tecnologias, como: instalação de totem com o mapa e localização dos estabelecimentos para PcD e clientes; implantação de rede WIFI e sistema on-line para o cliente fazer o pedido e o pagamento da conta; criação de aplicativos para divulgação e promoção 
da venda de produtos de forma "on-line", atendendo o cliente em outras áreas da cidade por meio de entrega em domicílio; instalação de Circuito Fechado de TV (CFTV) para monitoramento e segurança eletrônica com monitoramento também por meio de aplicativo no celular do proprietário.

\subsection{Relacionamento com Agentes Internos e Externos (Startups, Associações e Cooperativas) para Fortalecer o Ambiente}

Com o intuito de fortalecer a Vila Caramuru em termos de ambiente, sugere-se a realização de workshop entre startups, proprietários e concessionária para estabelecer fluxo de integração de sistemas e meios legais para aumento de rentabilidade, qualidade de produto de infraestrutura e de atendimento por meio de:

a) Sistema de controle de estoque e compra de material.

b)Instalação de cardápio on-line.

c) Criação de aplicativo para pedido on-line.

d)Divulgação por meio de marketing para mídias sociais.

e) Sustentabilidade por meio de instalação das placas solares e sistema para captação de águas pluviais.

f) Criação de associação para gestão de assuntos de interesses comuns, contemplando reuniões mensais, organização de eventos para divulgação do espaço, acordos para contratação de shows e organização de cursos de capacitação voltados para atendimento ao cliente.

g) Prover o espaço de coleta seletiva por meio da instalação de lixeiras para a separação do lixo e intercâmbio com associação de reciclagem para realizar a coleta; propor o intercâmbio entre os proprietários dos estabelecimentos da Vila e a Cooperativa dos pescadores, visando a uma sensibilização para a compra dos seus pescados; e, por fim, promover maior divulgação do empreendimento junto à rede hoteleira local para incentivar a visita dos turistas, haja vista o potencial para a atração deles.

Além disso, para resolver a questão da poluição sonora sugere-se que seja alinhado entre os proprietários dos estabelecimentos um limite de volume do som a ser seguido por todos. Quanto à contratação de bandas, sugere-se que o custo seja compartilhado pelos estabelecimentos e seja adotada uma agenda com programação mensal e que o palco de apresentação seja móvel, dessa forma, em cada show, a localização se daria em função dos estabelecimentos que estão compartilhando o custo. Outra possibilidade seria montagem do palco na área do estacionamento no fundo da Vila.

\section{Considerações Finais}

A proposta de revitalização do Mercado do Peixe reflete a lógica da administração pública da cidade em transferir para a iniciativa privada a exploração dos espaços públicos da orla de Salvador, $\mathrm{O}$ que evidencia que a reconstrução do espaço ocorreu de forma excludente desprezando fatores sociais, históricos, culturais que originaram esse espaço. 
A última reforma do espaço elevou o custo da concessão dos estabelecimentos e, com isso, a maioria dos comerciantes que atuavam no local teve que se retirar do Mercado, dando espaço para os grandes empresários com maior poder financeiro. Essa reforma também excluiu os Pescadores da dinâmica do local, o que evidencia a transferência do espaço público para o poder privado, demonstrando que o processo de revitalização urbana na cidade segue a lógica inversa ao desenvolvimento sustentável que requer desenvolvimento de atividades que gerem empregos, a inclusão e uma melhor qualidade de vida dos habitantes.

Observou-se que, apesar do alto investimento aplicado na última reforma, algumas deficiências permanecem e precisam ser sanadas para o bom funcionamento do espaço. A proposta aqui apresentada pretende atender às necessidades dos comerciantes do local para, também, atender melhor ao público usuário, por meio de uma intervenção para inovação e sustentabilidade da Vila, considerando a integração do estabelecimento dos pescadores e a humanização da Vila com mais áreas verdes, acessibilidade e áreas de convivência. Almeja-se ainda a utilização de tecnologias inovadoras, contando com a participação de startups para a implementação $e$ consolidação delas, visando ao desenvolvimento e à sustentabilidade da Vila Caramuru.

\section{Referências}

BAHIA. (Estado). Empresa Baiana de Águas e Saneamento (EMBASA). Ações da Embasa em Salvador. Outubro de 2013. Disponível em: http://www.embasa.ba.gov.br/images/ documents/1124/20180809_REV_AcoesdaEmbasaemSalvador.pdf. Acesso em: 2 set. 2019.

BARROS, Samuel. Mercado do Peixe, Largo da Mariquita, Rio Vermelho. Novembro, 2009. Disponível em: http://www.lupa.facom.ufba.br/2009/11/mercado-do-peixe-largo-da-mariquita-riovermelho/. Acesso em: 2 nov. 2018.

BARDIN, Laurence. Análise de conteúdo. 4. ed. Lisboa: Edições70, 2010.

BLOG DO RIO VERMELHO. As várias transformações do Mercado do Peixe. Fevereiro de 2016. Disponível em: https://blogdoriovermelho.blogdoriovermelho. blogspot.com/2016/02/as-variastransformacoes-do-mercado-do.html. Acesso em: 2 nov. 2018.

BLOG DO RIO VERMELHO. Terminal do Rio Vermelho décadas 50/60. Em 20 de agosto de 2015. Disponível em: https://blogdoriovermelho.blogspot.com/2015/08/o-coletivo-rio-vermelho-emacao.html. Acesso em: 28 jan. 2020.

BORTOLOZZO, Carolina Vittória Ortenzi. Proposta para a recuperação e requalificação de áreas subutilizadas no centro de São Paulo. $4^{\circ}$ Colóquio Brasil-Portugal, São Paulo. Novembro de 2016. Disponível em: https://www.mackenzie.br/fileadmin/ARQUIVOS/PUBLIC/SITES/PORTAL/ IV_COLOQUIO_BRASIL-PORTUGAL/9.pdf. Acesso em: 2 nov. 2018.

CMMD - COMISSÃO MUNDIAL SOBRE O MEIO AMBIENTE E DESENVOLVIMENTO. Nosso futuro comum. 2. ed. Rio de Janeiro: FGV, 1991. Disponível em: https://edisciplinas.usp.br/pluginfile. php/4245128/mod_resource/content/3/Nosso\%20Futuro\%20Comum.pdf. Acesso em: 2 nov. 2019.

DALLABRIDA, Valdir Roque; COVAS, Maria das Mercês Cabrita Mendonça; COVAS, António Manuel Alhinho. Inovação, desenvolvimento e espaço urbano: uma relação necessária, mas não suficiente. Rev. Bras. Estud. Urbanos Reg., Recife, v. 19, n. 2, p. 360-378, maio-ago., 2017. Disponível em: https://www.unc.br/mestrado/docs/ARTIGO\%20INOVA\%C3\%87\%C3\%83O\%20-\%20 RBPUR.pdf. Acesso em: 2 nov. 2019. 
FERNANDES, Inês Neto Capaz Coutinho. Requalificação do Espaço Público Urbano Caso de estudo - Bairro Olival de Fora. 2012. 64p. Dissertação (Mestrado) - Instituto Superior de Agronomia da Universidade Técnica de Lisboa, Lisboa, PT, 2012. Disponível em: https:/www. repository.utl.pt/bitstream/10400.5/5290/1/TESE_DEFINITIVA.pdf. Acesso em: 2 dez. 2018.

GUSMÃO, Roney. Requalificação pela desqualificação: o discurso da reurbanização no "novo" Rio Vermelho. Geousp - Espaço e Tempo, (on-line), v. 21, n. 2, p. 531-549, agosto, 2017. Disponível em: http://www.revistas.usp.br/geousp/article/view/121837. Acesso em: 10 dez. 2018.

PACHECO, Clarissa. Novo Mercado do Peixe reabre essa semana com 11 novos restaurantes.

Correio da Bahia, Salvador, BA, março de 2016. Disponível em: https://www.correio24horas.com.br/ noticia/nid/novo-mercado-do-peixe-reabre-essa-semana-com-11-novos-restaurantes/. Acesso em: $10 \mathrm{dez}$. 2018.

SANTOS, Clea Mota. Pescadores do Rio Vermelho: entre causos e lugares. 2014. 122p.

Dissertação (Mestrado) - Programa de Pós-Graduação em Crítica Cultural Pós-Critica/DEDC II Alagoinhas, 2014. Disponível em: http://www.poscritica.uneb.br/wp-content/uploads/2017/06/CLEAcr\%C3\%ADtica_cultural.pdf. Acesso em: 3 jan. 2019.

SANTOS, Patrícia Soares do Espírito; RIBEIRO, Renata Reis. Requalificação urbana nos

espaços de lazer de Salvador: uma análise do Parque Metropolitano de Pituaçu. 2015. 49p. TCC (Monografia) - Universidade da Integração Internacional da Lusofonia Afro-Brasileira, Redenção, CE, 2015. Disponível em: http://repositorio.unilab.edu.br:8080/jspui/bitstream/123456789/486/1/ Patricia\%20Soares\%20do\%20Espirito\%20Santo.pdf Acesso em: 10 dez. 2018.

\section{SEBRAE - SERVIÇO BRASILEIRO DE APOIO ÀS MICRO E PEQUENAS EMPRESAS.}

Planejamento estratégico: use a matriz F.O.F.A. para corrigir deficiências e melhorar a empresa. 2019. Disponível em: http://www.sebrae.com.br/sites/PortalSebrae/artigos/use-a-matriz-fofa-paracorrigir-deficiencias-e-melhorar-a-empresa,9cd2798be83ea410VgnVCM2000003c74010aRCRD. Acesso em: 2 set. 2019.

SILVA, Ana Dyenice Carlos da. Espaços Públicos: Requalificação dos Espaços de Lazer na Área Central da Cidade de Fortaleza. In: VII CONGRESSO BRASILEIRO DE GEÓGRAFOS. Vitória, ES, agosto, 2014. Anais [...], Vitória, ES, 2014. Disponível em:http://www.cbg2014.agb.org.br/resources/ anais/1/1404351835_ARQUIVO_ARTIGO-CGB.pdf. Acesso em: 10 dez. 2018.

TOSTA, Elza Hessel Tosta; NOLETO, Rodrigo de Andrade Costa. O papel do espaço público na construção da cidade compacta sustentável: as estratégias de projeto e os benefícios resultantes para uma sociedade urbana. In: V SIMPÓSIO NACIONAL DE GERENCIAMENTO DE CIDADES, $3^{\text {a }}$ SEMANA DE ARQUITETURA E URBANISMO DA UNIVAG. Várzea Grande, MT, 2017. Anais [...], Várzea Grande, MT, 2017. Disponível em: https://www.amigosdanatureza.org.br/eventos/data/ inscricoes/3408/form196411673.pdf. Acesso em: 2 set. 2019.

\section{Sobre os Autores}

\section{Thiago Messias Carvalho Soares}

E-mail: thiagoprofnit@gmail.com

Mestrando em Propriedade Intelectual e Transferência de Tecnologia para Inovação (PROFNIT).

Endereço profissional: PROFNIT-IFBA, Rua Emídio dos Santos, s/n, Barbalho, Salvador, BA. CEP: 40301-015. 


\section{Cidinei Paulo Campos}

E-mail: cidneicampos@gmail.com

Mestrando em Propriedade Intelectual e Transferência de Tecnologia para Inovação (PROFNIT).

Endereço profissional: PROFNIT-IFBA, Rua Emídio dos Santos, s/n, Barbalho, Salvador, BA. CEP: 40301-015.

\section{Marta Aparecida Rodrigues de Oliveira}

E-mail:mrodriveira@gmail.com

Mestrando em Propriedade Intelectual e Transferência de Tecnologia para Inovação (PROFNIT).

Endereço profissional: PROFNIT-IFBA, Rua Emídio dos Santos, s/n, Barbalho, Salvador, BA. CEP: 40301-015.

\section{Driele Lima Rocha}

E-mail: drielelimarocha@hotmail.com

Mestrando em Propriedade Intelectual e Transferência de Tecnologia para Inovação (PROFNIT).

Endereço profissional: PROFNIT-IFBA, Rua Emídio dos Santos, s/n, Barbalho, Salvador, BA. CEP: 40301-015.

\section{Eduardo Oliveira Teles}

E-mail: eduardo.teles@ifba.edu.br

Doutor em Engenharia Industrial (PEI/UFBA).

Endereço profissional: PROFNIT-IFBA, Rua Emídio dos Santos, s/n, Barbalho, Salvador, BA. CEP: 40301-015.

\section{Marcelo Santana Silva}

E-mail: profmarceloifba@gmail.com

Pós-Doutor pelo Programa de Pós-Graduação em Engenharia Industrial - (PEI/UFBA).

Endereço profissional: PROFNIT-IFBA, Rua Emídio dos Santos, s/n, Barbalho, Salvador, BA. CEP: 40301-015. 